\title{
Can a feedback report and training session on medication counseling for general practitioners improve patient satisfaction with information on medicines?
}

\author{
This article was published in the following Dove Press journal: \\ Patient Preference and Adherence \\ 7 March 2012 \\ Number of times this article has been viewed
}

\author{
Cornelia Mahler' \\ Katja Hermann' \\ Susanne Jank ${ }^{2}$ \\ Walter Emil Haefeli ${ }^{2}$ \\ Joachim Szecsenyi' \\ 'Department of General Practice \\ and Health Services Research, \\ ${ }^{2}$ Department of Clinical Pharmacology \\ and Pharmacoepidemiology, University \\ Hospital Heidelberg, Heidelberg, \\ Germany
}

Background: Regular intake of medicines prevents hospitalization and improves treatment outcomes in patients with chronic diseases; however, requires good patient-physician communication. Yet, this communication is often insufficient and characterized by misunderstandings. This paper aimed to explore whether a training session on medication counseling for general practitioners (GPs) can improve patient satisfaction about information on medicines.

Methods: Within a seamless care project $\left(\mathrm{HeiCare}^{\circledR}\right)$, a questionnaire to assess patient satisfaction with information on medicines and other questions related to medication issues was distributed among 370 patients. Results were returned to physicians in a feedback report, discussed in a training session, and a subsequent second questionnaire was sent to patients.

Results: Patients showed a significant increase in satisfaction with overall information on medicines and with information on potential problems when experiencing medication counseling after their GP received a feedback report and/or training session

Conclusion: Individual feedback and training sessions can improve medication counseling and GPs' awareness of patients' attitudes toward medicines and thus increase patients' satisfaction with medicines information received. Regular feedback to the GP on patients' satisfaction with information and patients' beliefs in medicines can be obtained by patient surveys or by addressing these issues in regular medication counseling encounters. Physicians need to be trained to listen to patients' views and concerns on medication.

Keywords: medication counseling, patient satisfaction, beliefs in medicines, feedback, general practice

\section{Introduction}

It is well known that information on medication and regular medication intake plays an important role in the successful treatment of diseases. ${ }^{1}$ This is acknowledged by all health care professionals and, therefore, a lot of effort has been put into supplying patients with information such as package inserts that follow recommendations for comprehensible medication information. ${ }^{2,3}$ In addition to written information, it is especially important to counsel patients with respect to the importance of following the prescribed regimen and on how to take the medication appropriately. ${ }^{4}$ The correct and reliable intake of medicines depends on the kind of information provided to the patients and on the information given to patients on the impact of medication regarding illness. ${ }^{5-7}$

General practice plays a pivotal role for medication prescribing and counseling, eg, in 2009 in Germany 52\% of medicines were prescribed by general practitioners
( Department of General Practice an Health Services Research, University Hospital Heidelberg, Vossstrasse 2, D-69I 5 Heidelberg, Germany Tel +49622I 566264 Fax +496221561972

Email cornelia.mahler@ med.uni-heidelberg.de 
(GPs) and $17 \%$ by internists involved in primary care. ${ }^{8}$ Especially patients on long-term medication need regular medication counseling at various stages: when renewing their prescription, when receiving additional medicines, for example, from specialists or for an acute episode, or when being discharged from hospital. Medication counseling at these stages can help identify adverse effects, interactions of medicines, and wrong application. In addition, patients' beliefs about medicines play an important role and can change over time due to formal and informal information patients receive via media, friends and relatives, and other health care professionals. ${ }^{9}$ These aspects as well as patient satisfaction with information on medicines have proven to have impact on medication adherence. ${ }^{10,11}$

However, there is often a mismatch in medication-related communication between patients and physicians, and medication counseling is therefore often not successful due to differences between patient and physician perception regarding the prescribed medication regimens. ${ }^{12,13}$ In addition, physicians overestimate the time they spend communicating about medications to patients, ${ }^{14}$ and that time is mostly spent with information on action and usage of medicines. ${ }^{15}$ Only a small proportion of time is spent on exploring patients' beliefs or concerns about medicines as well as other clinically relevant aspects such as possible interactions or nonadherence. ${ }^{16,17}$ Physicians are often not aware of patients who consider precisely these aspects as important. ${ }^{3}$ On the other side, patients often remain passive and seldom mention fears and concerns regarding medicines towards physicians. ${ }^{4}$ Communicating medication-related information that meets patients' needs is necessary so that patients are satisfied and subsequently take their medicines correctly and reliably. ${ }^{18}$

To raise awareness of patient needs regarding medication information and in order to change professional communication of GPs on medicine-related issues, training sessions for GPs on medication counseling are thus necessary.

Feedback has proven to be an effective method to change professional behavior and clinical performance among health professionals, ${ }^{19}$ especially when being compared with peers. ${ }^{20}$ In order to be effective, patient feedback provided to physicians needs to be based upon structured data and goals. ${ }^{21}$ Although physicians seem to be skeptical towards patient feedback, ${ }^{22}$ it can improve the physician-patient interaction. ${ }^{23} \mathrm{~A}$ systematic review indicated a positive impact on clinical performance when education was coupled with feedback being even more likely to be effective when provided by an authoritative source over an extended period of time. ${ }^{24}$
Within a project designed to improve medication communication across healthcare sectors (HeiCare ${ }^{\circledR}$ ), the aim was to investigate whether a multifaceted intervention to improve medication counseling had an impact on patient satisfaction with information on medicines. The HeiCare ${ }^{\circledR}$ project was conducted by the University Hospital Heidelberg in cooperation with a large compulsory health insurance fund. ${ }^{25}$ Fifty-six primary care practices participated in the project and enrolled 1002 patients. Inclusion criteria for patients were: long-term medication for a chronic disease, participation in a disease management program, and an expected hospitalization in the medium term. In general practices, patients' medication underwent a quality check, consisting of an internet-based knowledge database (AiDPraxis www.aidpraxis.de) checking for medication interactions and other drug-related problems, and a medication consultation with their GP. The internetbased knowledge database was also used to transfer medication data to the University Hospital Heidelberg when patients were admitted to hospital.

A primary patient survey (T0) (March-December 2007) using the Satisfaction with Information about Medicines Scale-German version (SIMS-D) ${ }^{26}$ identified that patients were mostly satisfied with the information they received on "action and usage" of medication but less satisfied with the information on "potential medication related problems" in general practice.

The aim of this study was to examine whether patients' satisfaction with information about medicines increases if their physicians receive feedback on their patients' satisfaction with information about medicines.

\section{Methods}

An intervention was conducted to investigate if a feedback report and a training session for GPs could improve medication counseling in general practice and hence patient satisfaction.

\section{Intervention}

The results of the primary survey mentioned above were summed up in a feedback report. To ensure patient anonymity it was only sent to GPs if at least ten of their patients had returned the questionnaire. This was the case with 19 of the participating GPs, who then received their feedback report in February 2008. The feedback report consisted of some introductory words regarding the survey procedure. In the following section patient results were displayed in comparison to the overall patient sample (benchmark): response rate, sociodemographic patient data, SIMS-D score, 
scale and subscale scores, Medication Adherence Report Scale-German version (MARS-D), ${ }^{27}$ and results on questions regarding medication management. The comparison with other practices allowed the GPs to identify their own strengths and weaknesses. The report concluded with some remarks on how to handle the results emphasizing that the patient sample may not be representative for the practice. It encouraged the GP to take a team approach when taking action for improvement.

The 19 GPs were then invited to attend a 120-minute training session on medication counseling (April 2008). Twelve physicians attended one of the two training sessions offered. Reasons given by the physicians for not being able to attend were time restrictions and other commitments. The sessions were conducted by $\mathrm{CM}$ and SJ and consisted of an indepth discussion of the patient assessment results. A reflection and exchange of personal strategies in medication counseling followed. Five bullet points for giving patients a guideline for effective medication counseling, which were based on literature and the findings of the survey, were given to the GPs:

- Ask patients if the medicines are being tolerated.

- Ask patients if they are taking further medicines (overthe-counter, ie, nonprescription, drugs).

- Adapt information to individual patient needs.

- Ensure that patients understand directions.

- Ask about fears and concerns regarding medication. GPs were then asked to set a personal goal for themselves in medication counseling in daily practice.

The training session was evaluated with a written survey consisting of nine questions on content, practical relevance of information, didactics, and organizational aspects on a scale ranging from "very good" (one) to "very bad" (six). The discussion was recorded in writing and audiotaped. Approval was obtained by the participating physicians as well as the Ethics Committee of the Medical Faculty of the University of Heidelberg.

\section{Questionnaire}

A second questionnaire (T1) was administered to the patients whose GP had attended the training session and/or received a feedback report at the end of July 2008. This date was chosen because in Germany patients with chronic diseases often visit their GP for a new prescription at the beginning of a quarter. It was assumed that by the end of the month most patients would have seen their GP.

T1 consisted of SIMS-D, ${ }^{11}$ MARS-D, three questions regarding medication management in the patient's general practice, and self-reported number of medicines. The Beliefs about Medicines Questionnaire (BMQ) ${ }^{28}$ as well as one question asking if the patient had experienced medication counseling with his GP in the last 10 weeks were also added. Patient's sociodemographic data (age, gender, education, self-reported diseases) had been collected with T0.

On enrolment, patients had agreed on participating in a voluntary patient survey, which had been approved by the Ethics Committee of the Medical Faculty of the University of Heidelberg.

\section{Measures SIMS-D}

SIMS-D, developed by Rob Horne in England, ${ }^{10}$ comprises 17 items which were derived from the recommendations of the Association of the British Pharmaceutical Industry. These give information on the type of information that patients need for a safe and accurate self-management of medication. It is a method of eliciting patients' views on medication information rather than defining the absolute quantity or quality of the information obtained. Patients are asked to rate each of the 17 aspects of the information they have received on their medication on a five-point scale: "too much," "about right," "too little," "none received," and "none needed." Overall satisfaction with information received can be calculated by summing all items; higher scores indicating a higher degree of total satisfaction. Summing items one to nine (subscale one) identifies satisfaction with information about "action and usage of medication" (scores ranging from zero to nine); items ten to 17 (subscale two) identify satisfaction with information about "potential problems of medication" (scores ranging from zero to eight). SIMS-D therefore identifies unmet medicines information needs from the perspective of the individual patient. This is important because the patients' views about their medicines influence adherence. ${ }^{10}$

\section{BMQ}

BMQ comprises 18 items and four scales. Two five-item scales assess patients' beliefs about the necessity of their specific prescribed medication for controlling their illness and their concerns about potential negative consequences of taking it ("necessity" and "concern" scales). Two fouritem scales assess patients' general beliefs about medicines regarding overuse and harm of medication ("general overuse" and "general harm" scales). Patients rate each question on a five-point scale ranging from "strongly disagree" (one) to "strongly agree" (five). Scores obtained for the individual items within each scale are summed to give a scale score 
ranging from five to 25 for the necessity and concern scales, and from four to 20 for the general harm and general overuse scales.

\section{Medication management}

Medication management was assessed by asking if the patient had received a printed medication list from the physician (yes/no), if the physician usually inquired about further medication being taken, and if the physician asked whether the medication prescribed was being tolerated, using five response alternatives ranging from "always" to "never."

\section{Patient sample and data collection}

The questionnaire was sent to the 370 patients who had returned T0 and whose physician had received a feedback report. As an incentive to fill in and send back the questionnaire, a monthly lottery drawing (two times 20 Euro) was conducted and a stamped envelope with the postal address of the University Hospital was enclosed. After 2 weeks a reminder was sent to those patients whose questionnaire had not been returned.

\section{Statistical analysis}

Data was entered and analyzed in IBM SPSS version 18.0 (SPSS Inc, Chicago, IL). Patients were divided into two groups retrospectively: Group A, patients who indicated that they had received medication counseling within the last 10 weeks $(\mathrm{N}=168)$; Group $\mathrm{B}$, patients who indicated that they had received no medication counseling within the last 10 weeks $(\mathrm{N}=63)$. Differences in sociodemographic data between Groups A and B were analyzed. Mean and standard deviation were calculated for the SIMS-D scores at T0 und T1 for both groups.

Data was analyzed using one-way repeated measures analysis of variance for Groups A and B to test whether the groups differed with regard to satisfaction with information about medicines (SIMS-D score) over time.

Scores for the BMQ (median and interquartile range) were calculated for Groups A and B at T1. To explore differences between groups, Mann-Whitney U test was applied.

\section{Results}

\section{Physician sample}

The 19 physicians who received a feedback report and/or took part in the training session had a mean age of 54.4 years (standard deviation [SD] 7.64 years) and 84.2\% were male. They had taken up residence since an average of 19.8 years
(SD 8.45 years). Seven of the practices (36.8\%) were solo practices and over half of the practices $(57.9 \%)$ were located in a rural area.

\section{Evaluation of the training session and feedback reports}

The training session was evaluated by all twelve participating physicians on a scale of "very good" (one) to "very bad" (six). Marks received were between 1.2 and 2.3, with a high average mark of 1.6. The following comments on the feedback report were given during the session:

- "I have become more aware of handing my patients a written medication plan. I thought I had always done so, but now I pay more attention to it." (GP1, Session 1)

- "... I realized that you have to enquire more, such as which medicines the patient buys himself. I was sensitized and rethink things now. For example, I now pay more attention to side effects. I had no idea in the beginning, but the feedback report was good. I ask (the patient) more now." (GP2, Session 2)

- "I also think the feedback reports are very good." (GP5, Session 2)

- "Since then I always ask the patients which medicines they buy additionally." (GP1, Session 2).

\section{Patient questionnaire}

Overall, 273 (73.4\%) patients sent back the questionnaire. In 41 questionnaires the SIMS-D showed missing values, leaving 232 (62.7\%) pairs at T0 and T1 to analyze (Figure 1). One hundred and sixty-eight $(72.4 \%)$ patients indicated that they had experienced medication counseling within the past 10 weeks with their GP.

\section{Sample}

Demographic data at T0 revealed that the overall sample was 68.7 years old and $56.3 \%$ were male. No significant differences in sociodemographic characteristics between Groups A and B were found, however a significant increase was identified for Group A in the number of medicines taken between T0 and T1 (Wilcoxon test $P<0.01$ ) (Table 1).

\section{Satisfaction with information about medicines}

For patients who had received medication counseling in the past 10 weeks, all SIMS-D scores increased between T0 and T1. For the 63 patients in Group B who had received no medication counseling in the past 10 weeks, satisfaction with information about medicines decreased in all scores (Table 2). 


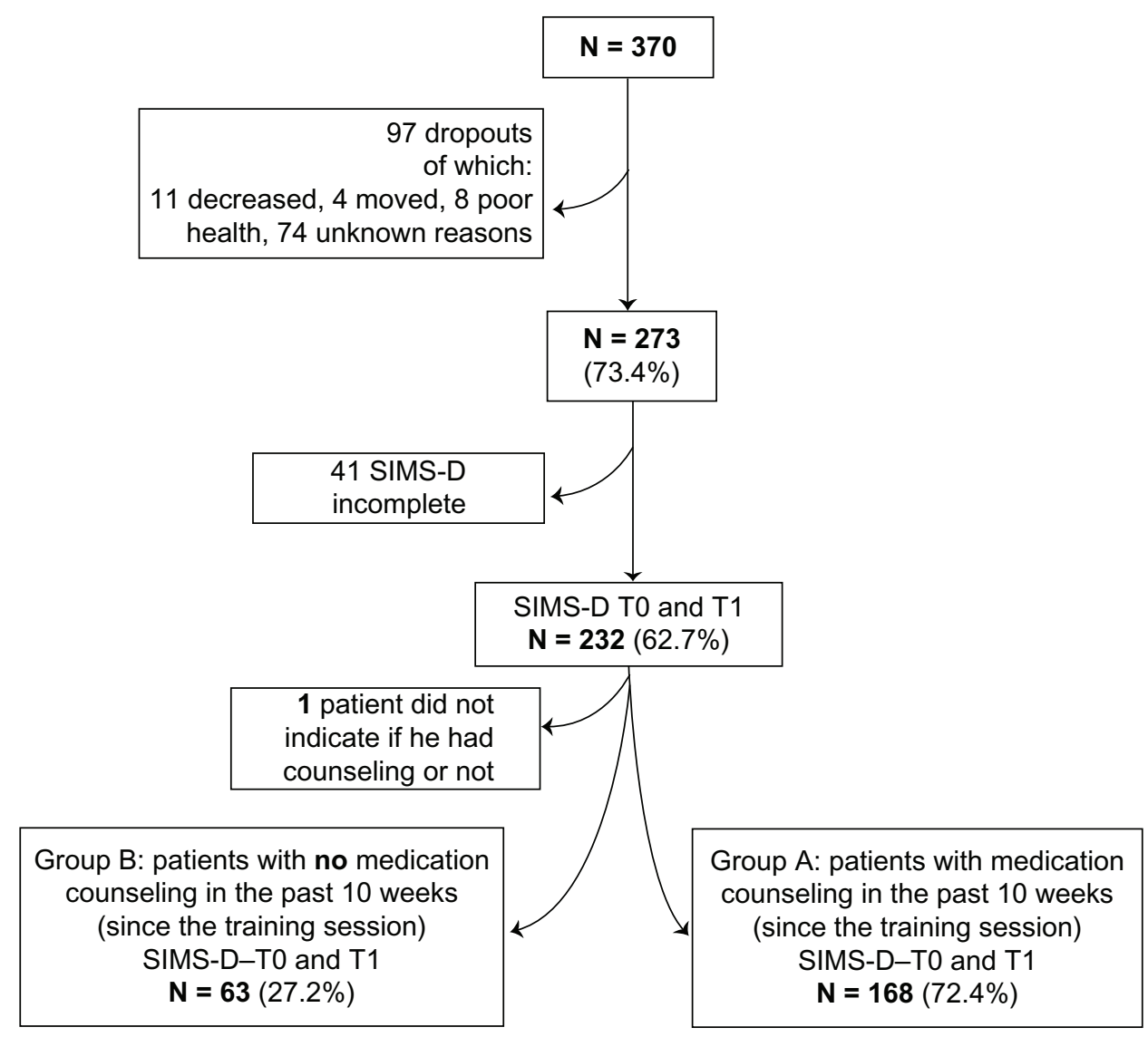

Figure I Flow chart of the administration process of the study.

Abbreviations: SIMS-D, Satisfaction with Information about Medicines Survey-German version; T0, primary patient survey; TI, second questionnaire administered to patients whose general practitioner had attended the training session and/or received a feedback report.

Table I Sociodemographic data, number of diseases, and number of medicines in the overall sample and both subgroups

\begin{tabular}{|c|c|c|c|}
\hline & $\begin{array}{l}\text { Overall sample } \\
(N=232)\end{array}$ & $\begin{array}{l}\text { Group A: medication counseling } \\
\text { had taken place }(N=168)\end{array}$ & $\begin{array}{l}\text { Group B: medication } \\
\text { counseling had not } \\
\text { taken place }(N=63)\end{array}$ \\
\hline Age $(\mathrm{T} 0)(\mathrm{N}=23 \mathrm{I} / 168 / 62)$ & 68.7 & 68.7 & 66.7 \\
\hline Mean age in years (range) & $(19-95)$ & $(19-95)$ & $(44-85)$ \\
\hline Gender male $(\%)(N=231 / 168 / 62)$ & 56.3 & 55.4 & 58.1 \\
\hline Mother tongue German $(\%)(\mathrm{N}=22 \mathrm{I} / 160 / 6 \mathrm{I})$ & 94.1 & 93.8 & 95.1 \\
\hline Number of diseases (T0) Mean (range) & 3.5 & 3.5 & 3.4 \\
\hline$(N=232 / 168 / 63)$ (self report) & $(\mathrm{I}-8)$ & $(\mathrm{I}-8)$ & $(1-7)$ \\
\hline \multicolumn{4}{|c|}{ Number of medicines T0 (\%) $(\mathrm{N}=228 / \mathrm{l} 65 / 62)$ (self report) } \\
\hline $1-3$ & 22.4 & 23.6 & 19.4 \\
\hline $4-7$ & 50.0 & 46.7 & 58.1 \\
\hline $8-10$ & 17.5 & 18.2 & 16.1 \\
\hline$>10$ & 10.1 & 11.5 & 6.5 \\
\hline \multicolumn{4}{|c|}{ Number of medicines $\mathrm{TI}(\%)(\mathrm{N}=232 / 168 / 63)$ (self report) } \\
\hline $1-3$ & 16.8 & 17.3 & 15.9 \\
\hline $4-7$ & 52.2 & 49.4 & 58.7 \\
\hline $8-10$ & 19.4 & 19.0 & 20.6 \\
\hline$>10$ & 11.6 & 14.3 & 4.8 \\
\hline $\begin{array}{l}\text { Wilcoxon test for number of medicines in each } \\
\text { group between } \mathrm{T} 0 \text { and } \mathrm{TI}\end{array}$ & & $P<0.01$ & $P=0.491$ \\
\hline
\end{tabular}

Abbreviations: T0, primary patient survey; TI, second questionnaire administered to patients whose general practitioner had attended the training session and/or received a feedback report. 
Table 2 Satisfaction with Information about Medicines Survey scores at T0 and TI

\begin{tabular}{|c|c|c|c|c|c|c|c|c|}
\hline & \multicolumn{4}{|c|}{$\begin{array}{l}\text { Group A: medication counseling had } \\
\text { taken place } \\
(\mathrm{N}=168)\end{array}$} & \multicolumn{4}{|c|}{$\begin{array}{l}\text { Group B: medication counseling } \\
\text { had not taken place } \\
(\mathrm{N}=63)\end{array}$} \\
\hline & \multicolumn{2}{|l|}{ T0 } & \multicolumn{2}{|l|}{ TI } & \multicolumn{2}{|l|}{ T0 } & \multicolumn{2}{|l|}{ TI } \\
\hline & $\overline{\text { Mean }}$ & SD & Mean & SD & Mean & SD & Mean & SD \\
\hline SIMS-D: overall satisfaction & 12.1 & 4.35 & 12.7 & 4.23 & 10.0 & 5.42 & 9.1 & 5.44 \\
\hline SIMS-D: action and usage & 7.2 & 2.16 & 7.6 & 2.13 & 6.3 & 2.81 & 6.2 & 2.80 \\
\hline $\begin{array}{l}\text { SIMS-D: potential problems } \\
\text { of medication }\end{array}$ & 4.9 & 2.71 & 5.2 & 2.79 & 3.7 & 3.21 & 3.0 & 2.01 \\
\hline
\end{tabular}

Abbreviations: SD, standard deviation; SIMS-D, Satisfaction with Information about Medicines Survey-German version; T0, primary patient survey; TI, second questionnaire administered to patients whose general practitioner had attended the training session and/or received a feedback report.

One-way repeated measures analysis of variance revealed no difference over time within the whole group. A difference was found over time between the groups regarding SIMS-D overall satisfaction $(\mathrm{F}[1,229]=5.07, P=0.025)$ and the subscale potential problems of medication $(\mathrm{F}[1,229]=5.86$, $P=0.017)$. No difference between the groups over time was revealed for the subscale action and usage of medication $(\mathrm{F}[1,229]=1.83, P=0.178)($ Table 3$)$.

\section{Beliefs in medicines}

BMQ showed no significant differences between the two groups for specific necessities and specific concerns about medicines however a difference was detected in general overuse and general harm scales showing that patients who didn't receive medication counseling (Group B) had higher scores in these two scales (Table 4).

\section{Discussion}

Patients showed a significant increase in satisfaction with overall information on medicines and with information on potential problems when experiencing medication counseling after their GP received a feedback report and/or training session. Looking at the whole sample over time, no significant difference in satisfaction could be found; however, patients' satisfaction differed significantly between the two groups with and without medication counseling after their GPs attended the training session. This can be assumed to be a result of the intervention directing physicians' attention to medication counseling considering that usually information on action and usage is communicated by physicians. ${ }^{29,30}$ Satisfaction with information on medicationrelated problems increased especially for those patients who received medication counseling, suggesting that physicians may have paid more attention to address these issues when talking about medicines. The comments of the physicians on the feedback report support these findings.

Patients who didn't receive medication counseling (Group B) seemed to be more skeptical and concerned about general harm and overuse of medicines than patients in Group A. This may be due to different individual concepts of illness, ${ }^{31,32}$ and could be a reason why they did not have medication counseling in the 10 weeks prior to $\mathrm{T} 1$ despite the fact that multimorbid patients in Germany visit a physician, on average, twelve times a year. ${ }^{33}$ Especially for these patients, regular and planned medication reviews with a health professional may help increase patient satisfaction by addressing patients' individual information needs as well as their beliefs and concerns regarding medicines.

The results support findings that feedback combined with a training session can support change in professional behavior. ${ }^{19,34}$ However, one feedback report and one training session are most likely not sufficient to sustain long-term change. Ongoing training and reflection of professional behavior is therefore required.

There are limitations to the study that merit discussion. Firstly, a causal relationship between feedback report/ training session and increase in patient satisfaction cannot be drawn because many factors such as beliefs in medicines, ${ }^{31}$ individual concepts, ${ }^{32}$ or perceived health status ${ }^{35}$ can

Table 3 One-way repeated measures analysis of variance

\begin{tabular}{lll}
\hline & Factor & Factor *group \\
\hline SIMS-D: overall satisfaction & $\mathrm{F}(\mathrm{I}, 229)=0.062 P=0.803$ & $\mathrm{~F}(\mathrm{I}, 229)=5.07 P=0.025 *$ \\
SIMS-D: action and usage & $\mathrm{F}(\mathrm{I}, 229)=0.4 I 2 P=0.52 \mathrm{I}$ & $\mathrm{F}(\mathrm{I}, 229)=1.83 P=0.178$ \\
SIMS-D: potential problems & $\mathrm{F}(\mathrm{I}, 229)=0.905 P=0.342$ & $\mathrm{~F}(\mathrm{I}, 229)=5.86 P=0.017^{*}$ \\
\hline
\end{tabular}

Note: *Shows statistical significance $(P<0.05)$.

Abbreviations: SIMS-D, Satisfaction with Information about Medicines Survey-German version. 
Table 4 Beliefs in Medicines Questionnaire scores at TI

\begin{tabular}{|c|c|c|c|c|c|c|c|}
\hline & \multicolumn{3}{|c|}{$\begin{array}{l}\text { Group A: medication counseling had } \\
\text { taken place }\end{array}$} & \multicolumn{3}{|c|}{$\begin{array}{l}\text { Group B: medication counseling had } \\
\text { not taken place }\end{array}$} & \multirow{2}{*}{$\begin{array}{l}\text { Mann-Whitney } \\
\mathbf{U} \text { test } \\
P \text { values }\end{array}$} \\
\hline & $\mathbf{N}$ & Median & IQR & $\mathbf{N}$ & Median & IQR & \\
\hline Specific necessities & 164 & 24.0 & $20.0-25.0$ & 60 & 23.0 & $21.0-25.0$ & 0.28 \\
\hline \multicolumn{8}{|l|}{ Range 5-25 } \\
\hline Specific concerns & 166 & 13.0 & $10.0-18.0$ & 62 & 15.0 & $9.0-17.0$ & 0.15 \\
\hline \multicolumn{8}{|l|}{ Range 5-25 } \\
\hline General overuse & 161 & 12.0 & $11.0-16.0$ & 63 & 13.0 & $8.0-14.0$ & $<0.0 I^{*}$ \\
\hline \multicolumn{8}{|l|}{ Range 4-20 } \\
\hline General harm & 164 & 8.0 & $7.0-11.25$ & 62 & 9.0 & $6.0-10.0$ & $0.04 *$ \\
\hline Range 4-20 & & & & & & & \\
\hline
\end{tabular}

Note: *Shows statistical significance $(P<0.05)$.

Abbreviations: IQR, interquartile range; TI, second questionnaire administered to patients whose general practitioner had attended the training session and/or received a feedback report.

also influence patients' satisfaction with information on medicines. In addition, the sample represents only motivated GPs who were willing to participate in the HeiCare ${ }^{\circledR}$ project, attend the training sessions, and reflect on professional behavior, maybe leading to biased results. Patients were asked whether they received medication counseling; however, it is not known what the counseling situation consisted of and in which situation the physician-patient communication about medication occurred.

These results cannot be generalized as no random assignment to the groups was performed and no comparison of patients with nontrained GPs was possible in this study.

\section{Conclusion}

Individual feedback and training sessions seem to help improve medication counseling and GPs' awareness of patients' attitudes toward medicines, thus increasing patients' satisfaction with medicines information received. Training on medication counseling is an ongoing process and physicians need to be accompanied over a longer period of time to change professional behavior in medication counseling from an incidental event at the end of a consultation to a proactive and regular patient-centered encounter. Individualized information concerning potential drug-related problems and medicine taking should be addressed in regular medication reviews helping to ensure medication safety.

Patients need to be given an opportunity to express their own beliefs and concerns about medication, which will also increase patient satisfaction. Results from patient surveys can be used in feedback reports and training sessions to help physicians reflect on their professional behavior and to encourage them to focus on patient-centered medication issues. This will lead to higher patient satisfaction and can help patients adhere to medication regimens supporting their treatment.

\section{Acknowledgments}

Sponsor of the research is AOK Baden-Württemberg, a compulsory health insurance fund.

\section{Disclosures}

The authors report no conflicts of interest in this work. The publication of the study results was not contingent on the sponsor's approval.

\section{References}

1. Laufs U, Rettig-Ewen V, Bohm M. Strategies to improve drug adherence. Eur Heart J. 2011;32(3):264-268.

2. Nink K, Schröder H. On Risks and Side Effects: Do You Read the Package Insert? Bonn; Wissenschaftliches Institut der AOK; 2005. German.

3. Peveler R, George C, Kinmonth AL, Campbell M, Thompson C. Effect of antidepressant drug counselling and information leaflets on adherence to drug treatment in primary care: randomised controlled trial. $B M J$. 1999;319(7210):612-615.

4. Cox K, Stevenson F, Britten N, DundarY. A Systematic Review of Communication Between Patients and Health Care Professionals About MedicineTaking and Prescribing. London: Medicines Patnership; 2004.

5. Barat I, Andreasen F, Damsgaard EM. Drug therapy in the elderly: what doctors believe and patients actually do. Br J Clin Pharmacol. 2001;51(6):615-622.

6. Field K, Ziebland S, McPherson A, Lehman R. "Can I come off the tablets now?" A qualitative analysis of heart failure patients' understanding of their medication. Fam Pract. 2006;23(6):624-630.

7. Hobbs FD. Concordance with heart failure medications: what do patients think? Fam Pract. 2006;23(6):607-608.

8. Schwabe U, Paffrath D, editors. Arzneiverordnungs Report 2010 : Current Data, Costs, Trends and Comments. Berlin: Springer-Verlag; 2010. German.

9. Schneider MP, Spirig R. Adherence: an important element in the care of chronical patients. Manag Care. 2006;3:18-21. German.

10. Horne R, Hankins M, Jenkins R. The Satisfaction with Information about Medicines Scale (SIMS): a new measurement tool for audit and research. Qual Health Care. 2001;10(3):135-140.

11. Mahler C, Jank S, Hermann K, et al. Psychometric properties of a German version of the "Satisfaction with Information about Medicines Scale" (SIMS-D). Value Health. 2009;12(8):1176-1179.

12. Bikowski RM, Ripsin CM, Lorraine VL. Physician-patient congruence regarding medication regimens. J Am Geriatr Soc. 2001;49(10):1353-1357. 
13. McKinley BT, Mulhall BP, Jackson JL. Perceived versus actual medication regimens among internal medicine patients. Mil Med. 2004; 169(6):451-454.

14. Makoul G, Arntson P, Schofield T. Health promotion in primary care: physician-patient communication and decision making about prescription medications. Soc Sci Med. 1995;41(9):1241-1254.

15. Sleath B, Roter D, Chewning B, Svarstad B. Asking questions about medication: analysis of physician-patient interactions and physician perceptions. Med Care. 1999;37(11):1169-1173.

16. Richard C, Lussier MT. Nature and frequency of exchanges on medications during primary care encounters. Patient Educ Couns. 2006;64(1-3):207-216.

17. Richard C, Lussier MT. Measuring patient and physician participation in exchanges on medications: dialogue ratio, preponderance of initiative, and dialogical roles. Patient Educ Couns. 2007;65(3): 329-341.

18. Ley P. Communicating with Patients. Improving Communication, Satisfaction and Compliance. New York: Croom Helm; 1988.

19. Bloom BS. Effects of continuing medical education on improving physician clinical care and patient health: a review of systematic reviews. Int J Technol Assess Health Care. 2005;21(3):380-385.

20. Jamtvedt G, Young JM, Kristoffersen DT, Thomson O'Brien MA, Oxman AD. Audit and feedback: effects on professional practice and health care outcomes. Cochrane Database Syst Rev. 2003(3): CD000259.

21. Evans RG, Edwards A, Evans S, Elwyn B, Elwyn G. Assessing the practising physician using patient surveys: a systematic review of instruments and feedback methods. Fam Pract. 2007;24(2): $117-127$.

22. Wensing M, Vingerhoets E, Grol R. Feedback based on patient evaluations: a tool for quality improvement? Patient Educ Couns. 2003;51(2):149-153.

23. Greco M, Brownlea A, McGovern J. Impact of patient feedback on the interpersonal skills of general practice registrars: results of a longitudinal study. Med Educ. 2001;35(8):748-756.

24. Veloski J, Boex JR, Grasberger MJ, Evans A, Wolfson DB. Systematic review of the literature on assessment, feedback and physicians' clinical performance: BEME Guide No. 7. Med Teach. 2006;28(2): $117-128$.
25. Mahler C, Jank S, Pruszydlo MG, et al. HeiCare ${ }^{\circledR}$ : a project aiming to improve medication communication across health care sectors. Dtsch Med Wochenschr. 2011;136(44):2239-2244. German.

26. Mahler C, Jank S, Hermann K, Haefeli WE, Szecsenyi J. Information on medications - how do chronically ill patients assess counselling on drugs in general practice? Dtsch Med Wochenschr. 2009;134(33):1620-1624. German.

27. Mahler C, Hermann K, Horne R, et al. Assessing reported adherence to pharmacological treatment recommendations. Translation and evaluation of the Medication Adherence Report Scale (MARS) in Germany. J Eval Clin Pract. 2010;16(3):574-579.

28. Opitz U, Glattacker M, Bengel J, Jäckel WH, Horne R. The "Beliefs about Medicines Questionnaire” (BMQ ${ }^{\circledR}$ R Horne) - translation and preliminary testing among patients with fibromyalgia. Paper presented at: Rehabilitation Science Colloquium; March 3-5, 2008; Bremen, Germany. German.

29. Tarn DM, Heritage J, Paterniti DA, Hays RD, Kravitz RL, Wenger NS. Physician communication when prescribing new medications. Arch Intern Med. 2006;166(17):1855-1862.

30. Tarn DM, Paterniti DA, Heritage J, Hays RD, Kravitz RL, Wenger NS. Physician communication about the cost and acquisition of newly prescribed medications. Am J Manag Care. 2006;12(11):657-664.

31. Horne R. Treatment perceptions and self-regulation. In: Cameron LD, Leventhal H, editors. The Self-Regulation of Health and Illness Behaviour. London: Routledge; 2003:138-154.

32. Weinman J. Health Care. In: Johnston DW, Johnston M, editors. Health Psychology: Comprehensive Clinical Psychology, Volume 8. Oxford: Pergamon Press; 2001:79-112.

33. Advisory Council on the Assessment of Developments in the Health Care System. Coordination and Integration - Health Care in an Ageing Society. 2009. Available from: http://www.svr-gesundheit.de/ Gutachten/Gutacht09/KF\%20eng1\%20final.pdf. Accessed October 24, 2011.

34. Jamtvedt G, Young JM, Kristoffersen DT, O'Brien MA, Oxman AD. Does telling people what they have been doing change what they do? A systematic review of the effects of audit and feedback. Qual Saf Health Care. 2006;15(6):433-436.

35. Xiao H, Barber JP. The effect of perceived health status on patient satisfaction. Value Health. 2008;11(4):719-725.
Patient Preference and Adherence

\section{Publish your work in this journal}

Patient Preference and Adherence is an international, peer-reviewed, open access journal focusing on the growing importance of patient preference and adherence throughout the therapeutic continuum. Patient satisfaction, acceptability, quality of life, compliance, persistence and their role in developing new therapeutic modalities and compounds to

\section{Dovepress}

optimize clinical outcomes for existing disease states are major areas of interest. This journal has been accepted for indexing on PubMed Central. The manuscript management system is completely online and includes a very quick and fair peer-review system. Visit http://www.dovepress.com/ testimonials.php to read real quotes from published authors. 